\title{
Inactivation of mitochondrial Complex I stimulates chloroplast ATPase in Physcomitrella (Physcomitrium patens).
}

Marco Mellon ${ }^{a}$, Mattia Storti ${ }^{a}$, Antoni Mateu Vera Vives ${ }^{a}$, David M. Kramer ${ }^{b}$, Alessandro Alboresi ${ }^{a}$ and Tomas Morosinotto ${ }^{a}$

a. Department of Biology, University of Padova, 35121 Padova, Italy

b. MSU-DOE Plant Research Laboratory, Michigan State University, East Lansing, MI 48824, United States of America; Biochemistry and Molecular Biology, Michigan State University, East Lansing, MI 48824, United States of America.

Corresponding author: Tomas Morosinotto, Dipartimento di Biologia, Università di Padova, Via Ugo Bassi 58B, 35121 Padova, Italy.Tel. +390498277484,Email: tomas.morosinotto@unipd.it

\begin{abstract}
While light is the ultimate source of energy for photosynthetic organisms, mitochondrial respiration is still fundamental for supporting metabolism demand during the night or in heterotrophic tissues. Respiration is also important for the metabolism of photosynthetically active cells, acting as a sink for excess reduced molecules and source of substrates for anabolic pathways. In this work, we isolated Physcomitrella (Physcomitrium patens) plants with altered respiration by inactivating Complex I of the mitochondrial electron transport chain by independent targeting of two essential subunits. Results show that the inactivation of Complex I causes a strong growth impairment even in fully autotrophic conditions in tissues where all cells are photosynthetically active. Complex I mutants show major alterations in the stoichiometry of respiratory complexes while the composition of photosynthetic apparatus was substantially unaffected. Complex I mutants showed altered photosynthesis with higher yields of both Photosystems I and II. These are the consequence of a higher chloroplast ATPase activity that also caused a smaller $\Delta \mathrm{pH}$ formation across thylakoid membranes as well as decreased photosynthetic control on cytochrome $b 6 f$, possibly to compensate for a deficit in ATP supply relative to demand in Complex I mutants. These results demonstrate that alteration of respiratory activity directly impacts photosynthesis in $P$. patens and that metabolic interaction between organelles is essential in their ability to use light energy for growth.
\end{abstract}

\section{Introduction}

In photosynthetic organisms, sunlight powers the linear electron flow (LEF) from water to $\mathrm{NADP}^{+}$catalysed by two photosystems (PS), PSII and PSI, cytochrome $b_{6} f$ and ATPase, ultimately generating NADPH and ATP to sustain cellular metabolism. In photosynthetic organisms, mitochondrial respiration is also active with its specific electron transport pathway, or oxidative phosphorylation (OXPHOS). OXPHOS transfers electrons from the substrates NADH and succinate to molecular oxygen through the activity of enzymatic complexes localized in the inner mitochondrial membrane, Complexes I, II, III, IV. This electron transfer is coupled to the generation of electrochemical transmembrane gradient that drives the synthesis of ATP through ATP-synthase, also called complex V. The NADH dehydrogenase complex (Complex I, Cl) is the main site for electron insertion into the mitochondrial electron transport chain (METC) and it can provide up to $40 \%$ of the protons for mitochondrial ATP formation (Watt et al., 2010; Braun et al., 2014). In plants mETC electrons can also follow alternative routes, bypassing $\mathrm{Cl}$ via alternative NADH dehydrogenases (Lecler et al., 2012) and complex III / IV via the alternative terminal oxidase (AOX) (Dinant et al., 2001). These alternative routes partly uncouple the electron 
transport and the electrochemical transmembrane gradient, thus reducing the energy yield of respiration with beneficial effects especially in stress conditions (Zalutskaya et al., 2015), reducing ROS production from mETC (Møller, 2001; Vanlerberghe et al., 2020).

Respiration in photosynthetic organisms is essential to support energy demand during the night, in nonphotosynthetic tissues such as roots or in developmental stages where photosynthesis is not active (e.g. seed germination). An increasing set of evidence, however, underlines the importance of respiration also for sustaining optimal photosynthetic activity (Joliot and Joliot, 2008; Noguchi and Yoshida, 2008; Bailleul et al., 2015) with a strong functional link between chloroplasts and mitochondria bioenergetic metabolism (Cardol et al., 2003; Dutilleul et al., 2003; Schönfeld et al., 2004). In the diatom Phaeodacty/um tricornutum this was clearly shown by demonstrating that metabolites exchange between chloroplast and mitochondria is essential for carbon fixation (Bailleul et al., 2015). In another example of such a functional link, excess reducing power produced via photosynthesis can be routed to mitochondrial respiration, preventing over-reduction and eventual reactive oxygen species (ROS) production in the plastid (Noguchi and Yoshida, 2008; Zhang et al., 2012). AOX activity has also been shown to influence photosynthetic metabolism response to stresses when it consumes excess reductant while decreasing mitochondrial ATP synthesis (Cheung et al., 2015) and maintaining redox balance of plastoquinone pool (Yoshida and Noguchi, 2011; Vanlerberghe et al., 2020). Consistently, AOX protein level was shown to be linked to differences in chloroplast energetic balance, being induced under strong irradiance, suggesting the presence of regulation signals originated from photosynthetic ETC activity (Dahal et al., 2016).

Imbalances between the relative rates of production and consumption of ATP/NADPH utilization can lead to the build-up of reactive intermediates of electron transfer processes, driving the formation of harmful ROS (Eberhard et al., 2008; Li et al., 2009). Photosynthetic organisms evolved multiple regulatory mechanisms to balance light-dependent processes and metabolic exploitation of photosynthesis products. Examples of such mechanisms are the dissipation of excess excitation energy as heat (non-photochemical quenching, NPQ) or the photosynthetic control to reduce electron transport capacity at the level of cytochrome $b_{6} f$ and prevent over-reduction. Both mechanisms are activated by a decrease of lumenal $\mathrm{pH}$, that represents a major signal for regulation of photosynthesis (Eberhard et al., 2008; Li et al., 2009).

Consistently with the essential role of mitochondrial respiration in plants metabolism, Knock-Out (KO) mutants completely depleted in complex II (Leon et al., 2007), complex III (Colas Des Francs-Small and Small, 2014) and complex IV (Radin et al., 2015) are not viable and so far only knock-down plants have been isolated and studied. Mutants completely lacking mitochondrial $\mathrm{Cl}$ activity have instead been described in Arabidopsis (Kühn et al., 2015; Fromm et al., 2016a) as well as in Nicotiana tabacum (Vidal et al., 2007) where they showed a severe growth phenotype and alterations in germination, fertilization and pollen development (Fromm et al., 2016a). European mistletoe Viscum album can live without $\mathrm{Cl}$, but it is an obligate semi-parasite living on branches of trees, and thus its energy metabolism is expected to be remodelled (Senkler et al., 2018).

Differently from plants, a large number of respiratory mutants have instead been isolated in the green alga Chlamydomonas reinhardtii where they generally show strong phenotypes under heterotrophic conditions but grow similarly to WT under photoautotrophic conditions (Salinas et al., 2014; Larosa et al., 2018).

These differences suggest that the role of respiration on cells metabolism adapted during plants evolution, motivating for the investigation of species that diverged at different times during evolution. Non-vascular plants like the moss Physcomitrella (Physcomitrium patens) diverged from vascular plants ancestors early after land colonization and thus their study allows highlighting the first adaptation to the new environmental 
conditions. To assess how the biological role of respiration adapted during the evolution of photosynthetic organisms in this work, we generated $P$. patens plants depleted of active respiratory $\mathrm{Cl}$ and investigated effects on photosynthetic activity. Results show that the absence of $\mathrm{Cl}$ stimulates photosynthetic transport caused by more active chloroplast ATPase with alteration of $\mathrm{pmf}$ and $\Delta \mathrm{pH}$ across the thylakoid membranes and impairment of photosynthetic control.

\section{Results}

Complex I (CI) in eukaryotes is composed of over 40 subunits and, among them, 14 are highly conserved across kingdoms (Ligas et al., 2019). Plant $\mathrm{Cl}$ includes 9 additional subunits that form a carbonic anhydrase domain (Braun et al., 2014; Fromm et al., 2016a; Subrahmanian et al., 2016). NDUFA5 and NDUFB10 genes were selected to generate $P$. patens mutants depleted in $\mathrm{Cl}$ based on two criteria: i) they encoded for conserved proteins known to be essential for $\mathrm{Cl}$ activity in C. reinhardtii, A. thaliana or $\mathrm{H}$. sapiens (Barbieri et al., 2011; Rak and Rustin, 2014); ii) they were present in a single copy in P. patens nuclear genome, facilitating the generation of mutants and ensuring that any eventual phenotype would be readily assessable. NDUFA5 is localized in the hydrophilic region of the complex binding the substrate NADH (Figure 1A) and it is required for assembly and stability of the matrix arm of $\mathrm{Cl}$ in human mitochondria (Rak and Rustin, 2014). NDUFB10 deletion in C. reinhardtii impairs the assembly of the distal part of $\mathrm{Cl}$ membrane module (Figure 1A), responsible for the proton pumping activity coupled with the electron transfer (Barbieri et al., 2011).

$\mathrm{KO}$ lines for both genes were generated by homologous recombination-mediated gene targeting (Figure S1AB). Multiple independent KO lines for each gene were isolated and the insertion of DNA in the expected position of the genome was verified by PCR (Figure S1C). The loss of expression of the target gene was also confirmed by RT-PCR (Figure 1B). In the following results from one line per gene are reported, but at least 4 independent confirmed lines per gene were isolated per each genotype.

A

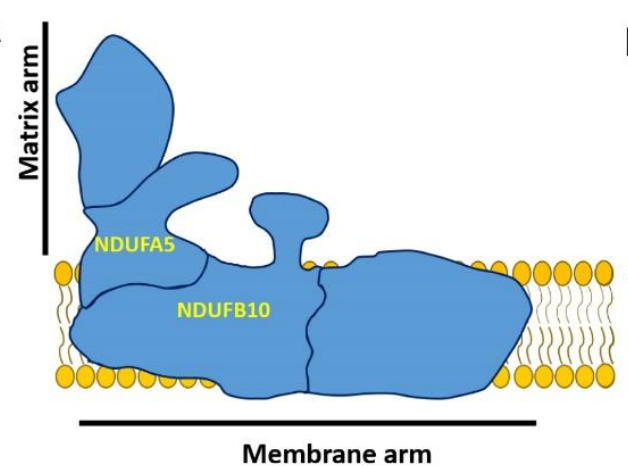

B

Pp Ndufa5

Pp Ndufb 10

Act.2

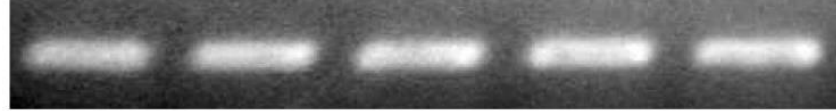

Figure 1. Generation of $P$. patens plants depleted in Complex I. A) Schematic representation of $\mathrm{Cl}$ structure with NDUFA5 and NDUFB10 localization. B) RT-PCR to assess the accumulation of the mRNA encoding for Ndufa5 and Ndufb10 in two independent KO lines.

All confirmed KO plants showed strongly impaired growth (Figure 2) that was visible upon cultivation on a glucose enriched medium but also on a mineral media in fully autotrophic conditions. Remarkably the growth defect was observed also if plants were grown autotrophically under 24 hours of continuous illumination, thus avoiding any dark time when respiration is expected to be essential (Figure 2). Glucose presence in the media and continuous illumination stimulated a faster growth in WT plants while the mutants remained unaffected (Figure S2). 


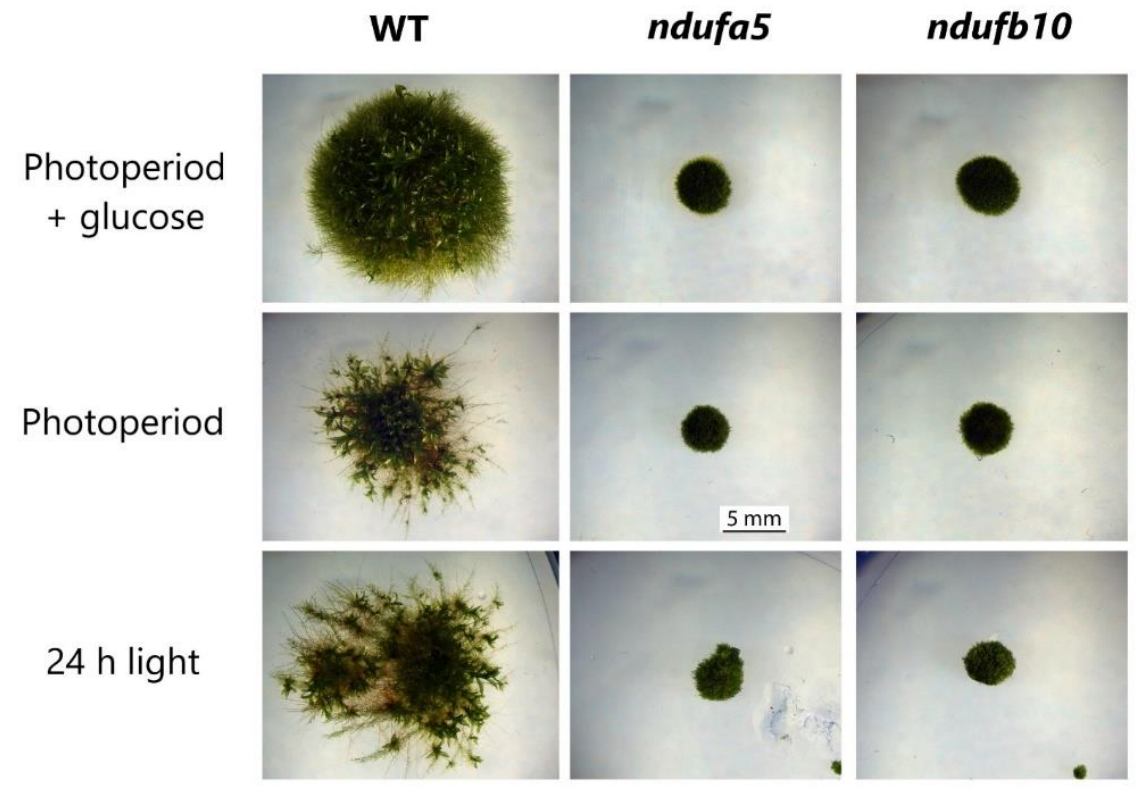

Figure 2. Impact of $\mathrm{Cl}$ inactivation on $P$. patens growth. WT, ndufb 10 and $n d u f a 5 \mathrm{KO}$ lines growth after 28 days under $16 \mathrm{~d} / 8 \mathrm{~h}$ dark photoperiod with/without the addition of $0.5 \%$ glucose in the media (top/middle respectively) or under 24 hours continuous illumination without glucose (bottom).

Impact of mutations on respiratory apparatus composition was assessed using specific antibodies (Figure 3A). NAD9, a Cl core subunit localized in the Q module of the matrix arm, was completely missing in ndufa5 mutant, consistently with recently reported evidence that NDUFA5 directly interacts with NAD9 during $\mathrm{Cl}$ biogenesis (Ligas et al., 2019). NAD9 was instead present in ndufb10 mosses suggesting that at least part of $\mathrm{Cl}$ was still present, as observed for other analogous mutants (Ligas et al., 2019). Both KO plants showed significant alterations in other complexes of the respiratory apparatus. While CIV and CV contents were unaltered, CII and $\mathrm{CIII}$ were more abundant in the mutants as compared to WT plants by respectively $\approx 3$ and 1.5 times. The most striking difference, however, was that AOX accumulated to approx. 10 times higher levels in ndufa 5 and ndufb10 than in WT. All differences in protein accumulation were consistent between the two independent mutant lines.

The impact of mutations on $\mathrm{Cl}$ was also assessed by blue native electrophoresis (BN-PAGE) on crude membrane extracts, containing both mitochondria and chloroplasts (Figure S3). The detection of $\mathrm{Cl}$ enzymatic activity after electrophoresis showed that in both mutant lines the correct assembly of $\mathrm{Cl}$ was compromised (Figure 3B). No Cl activity was detectable in the case of ndufa5. In the ndufb10 mutant, instead, the complete holoenzyme was absent but a partially assembled $\mathrm{Cl}$ retaining the NADH dehydrogenase activity was detectable (Complex I*, Figure 3B) consistently with earlier results in other species (Barbieri et al., 2011). 
A

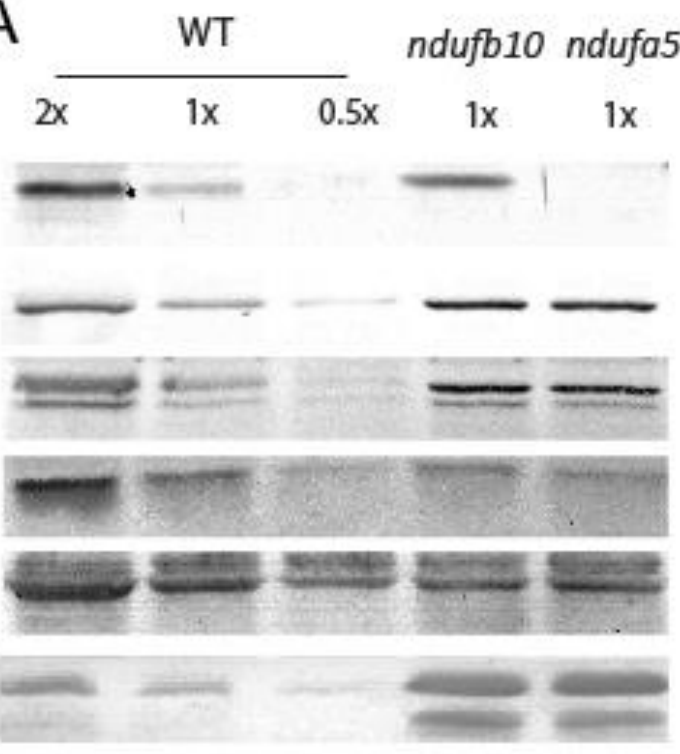

B

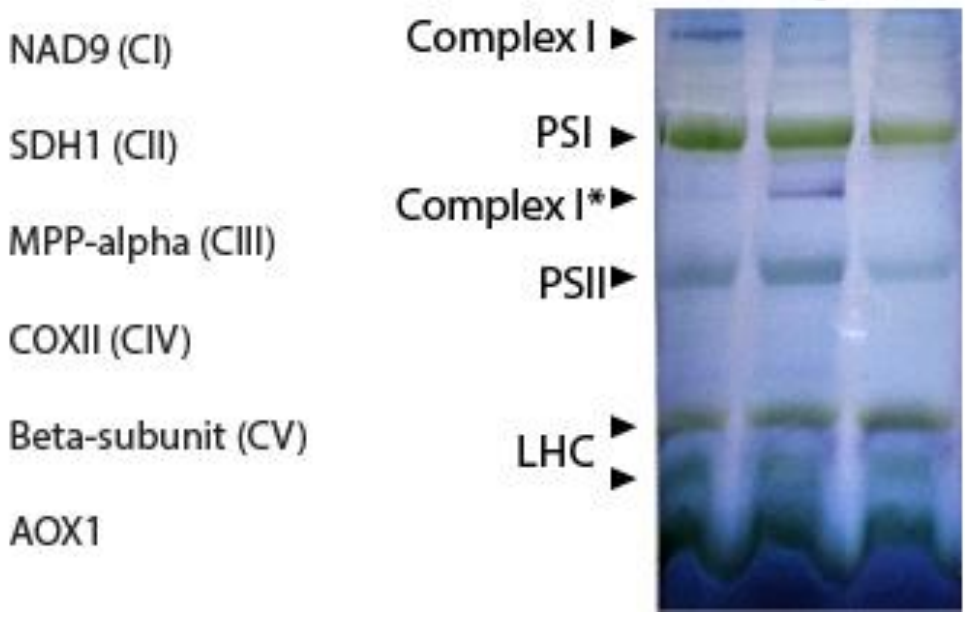

Figure 3. Impact of Complex I mutation on the respiratory apparatus composition and Complex I assembly. A) Immunoblot analysis using antibodies against various subunits of respiratory complexes. Total protein extracts were loaded, $1 \mathrm{X}$ samples correspond to $2 \mu \mathrm{g}$ of total chlorophyll. B) BN-PAGE separation of crude organelles extracts. Following separation (see Figure S3), $\mathrm{Cl}$ activity was detected with in-gel NADH/NBT staining. Membrane proteins from WT, ndufb10 and ndufa5 were solubilized with $1 \%$ of $\beta$-dodecyl maltoside $(\beta-D M)$. Main complexes of thylakoid and mitochondria complex I are indicated on the profiles. Complex I* indicates an assembly intermediate of complex I present in ndufb10; PSI, Photosystem I; PSII, photosystem II; LHC, light-harvesting chlorophyll complexes.

The impact of mutations on respiratory activity was assessed measuring oxygen $\left(\mathrm{O}_{2}\right)$ consumption rate. In both ndufa5 and ndufb10 plants, $\mathrm{O}_{2}$ consumption in the dark was higher than in WT (Figure 4). While this seems counterintuitive for mutants affected in a respiratory complex, this observation can be explained by the compensatory over-accumulation of $\mathrm{Cll}, \mathrm{CIII}$ and AOX. A similar increase in oxygen consumption was indeed observed also in Arabidopsis Cl mutants (Kühn et al., 2015). This hypothesis is confirmed by the observation that $\mathrm{O}_{2}$ consumption activity in ndufa5 and ndufb10 was completely insensitive to the addition of rotenone, a specific $\mathrm{Cl}$ inhibitor, that in WT plants instead reduced $\mathrm{O}_{2}$ consumption by $\approx 40 \%$ (Figure $4 \mathrm{~A}$ ).

Oxygen consumption activity was similarly reduced by the addition of KCN, a Complex IV inhibitor, in both WT and mutants (Figure 4B). The significant residual activity still present was mostly attributable to the presence of alternative oxidases like AOX, as confirmed by the further decrease in $\mathrm{O}_{2}$ evolution induced by its specific inhibitor SHAM (Figure 4C). While $2 \mathrm{mM}$ SHAM was a saturating dose for WT, a 4-fold higher dose was necessary to obtain a full inhibition in the mutants, consistent with their increased AOX content. Maximal photosynthetic $\mathrm{O}_{2}$ evolution activity was measured in the same samples upon exposition to saturating light. ndufa5 and ndufb10 KO mutants showed a reduction of $\approx 50 \%$ (Figure 4D). At least a major fraction of this reduction can, however, be explained by the higher $\mathrm{O}_{2}$ consumption rate in the mutants than in WT. 

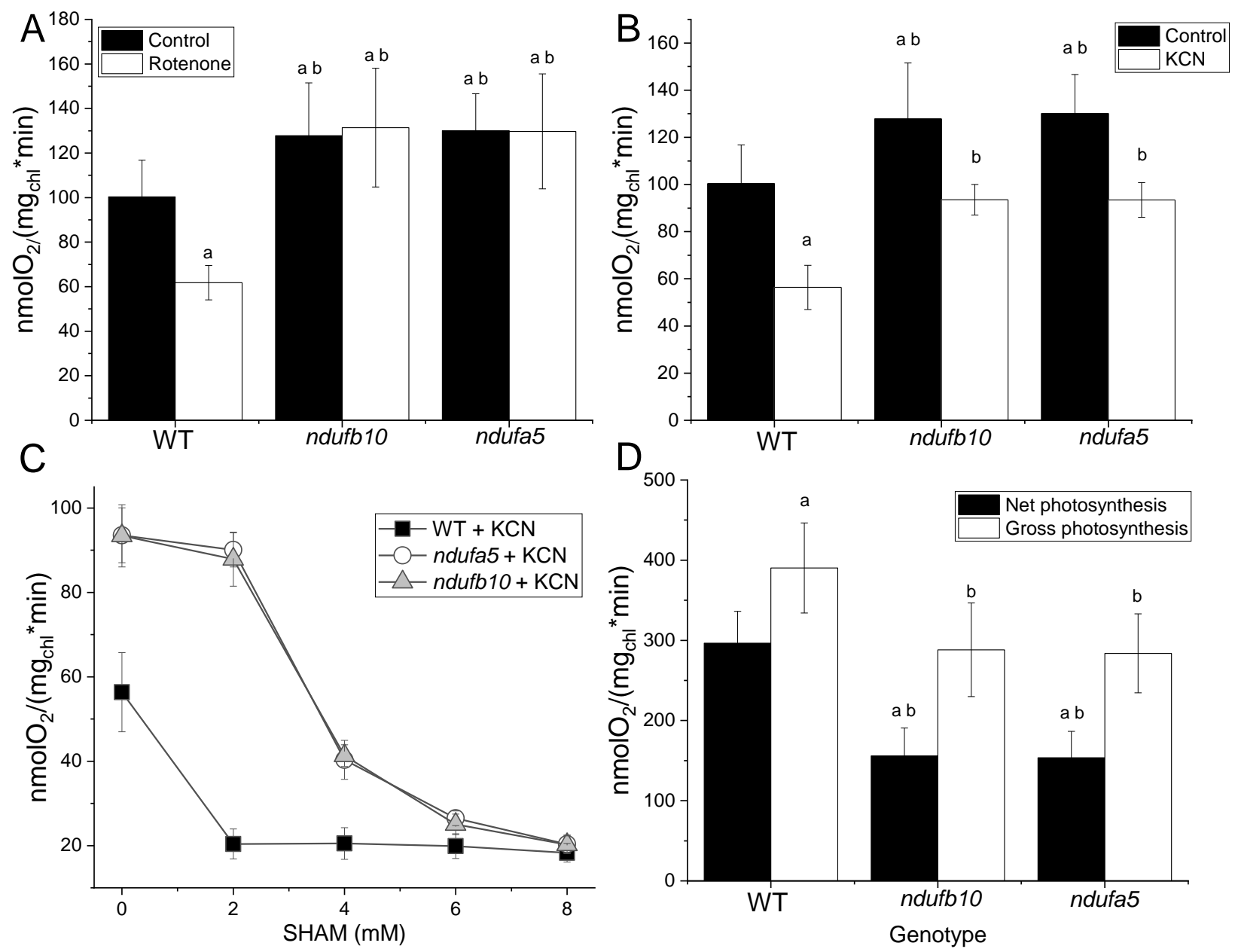

Figure 4. Oxygen consumption and evolution capacity in the ndufb10 and ndufa5. A) Oxygen consumption was monitored with a Clark-type oxygen electrode on WT and ndufb10 and ndufa5 plants grown for 10 days in minimal medium. Mosses were maintained in the dark in the absence (black) or presence of $50 \mu \mathrm{M}$ rotenone (white columns). B) Effect of cyanide $(\mathrm{KCN})$ on $\mathrm{O}_{2}$ consumption. Controls without the inhibitor are in black, samples with addition $1 \mathrm{mM} \mathrm{KCN}$ in white. In both panels "a" indicates a statistically significant difference compared to untreated WT, " $b$ " significant difference compared to WT treated with the same inhibitor (oneway ANOVA, $n>5, p<0.01$ ). C) Effect of different concentration of SHAM on $\mathrm{O}_{2}$ consumption in the presence of $1 \mathrm{mM} \mathrm{KCN}$. WT is showed as black square, ndufb10 as grey triangles, ndufa5 as white circles. Average \pm SD $(n \geq 5)$ are reported. D) Oxygen production of protonema illuminated with a light at $850 \mu$ mol photons $\mathrm{m}^{-2} \mathrm{~s}^{-1}$ measured with a Clark-type oxygen electrode. Net photosynthesis (black) is calculated directly from the $\mathrm{O}_{2}$ evolution rate during illumination. Gross photosynthesis (white) is calculated by adding net photosynthesis with oxygen consumption in the dark. In all panels average $\pm S D(n \geq 5)$ is reported. "a" indicates statistically significant difference compared to WT net oxygen evolution, " $b$ " indicates difference compared to WT gross $\mathrm{O}_{2}$ evolution (one-way ANOVA, $\mathrm{n}>5, \mathrm{p}<0.01$ ).

Impact of $\mathrm{Cl}$ depletion on photosynthesis.

Plants depleted of $\mathrm{Cl}$ showed reduced photoautotrophic grow and alterations in $\mathrm{O}_{2}$ evolution activity, motivating a deeper investigation of the impact of the mutation on photosynthetic activity. Chlorophyll (Chl) content, $\mathrm{Chl} \mathrm{a/b}$ and $\mathrm{Chl} / \mathrm{Car}$ ratio was unchanged in mutant and WT plants (Table 1). Consistently, the accumulation of all main components of the photosynthetic apparatus (PSI, PSII, cyt b6f, ATPase) showed no major alterations in the mutants except for a slight increase in chloroplast ATPase content (Figure S4). Subunits 
involved in regulatory mechanisms of photosynthesis such as PsbS and LHCSR (Alboresi et al., 2010) were also similarly accumulated in the mutants as in WT plants (Figure S4).

\begin{tabular}{|l|l|l|l|l|}
\hline Genotype & Chl a/Chl b & Chl/Car & $\begin{array}{l}\text { Chl content } \\
\left(\mu \mathrm{mg}^{-1} \mathrm{DW}\right)\end{array}$ & Fv/Fm \\
\hline WT & $2.62 \pm 0.14$ & $3.73 \pm 0.37$ & $18.5 \pm 2.7$ & $0.79 \pm 0.01$ \\
\hline ndufb10 & $2.59 \pm 0.20$ & $3.65 \pm 0.40$ & $18.9 \pm 3.0$ & $0.78 \pm 0.02$ \\
\hline ndufa5 & $2.64 \pm 0.21$ & $3.60 \pm 0.42$ & $18.7 \pm 2.7$ & $0.79 \pm 0.01$ \\
\hline
\end{tabular}

Table 1. Pigment composition and PSII quantum efficiency of $P$. patens WT and ndufb10 and ndufa5 mutant lines. Chlorophyll (Chl) a/b ratio, Chl / carotenoids (car) ratio, total Chl content and PSIl quantum yield (estimated by $\mathrm{Fv} / \mathrm{Fm}$ ) were evaluated in plants cultivated for 10 days in a minimal medium at $50 \mu \mathrm{mol}$ photons $\mathrm{m}^{-2} \mathrm{~s}^{-1}$. For each measurement average $\pm S D(n \geq 5)$ is reported.

Photosynthetic functionality was analysed in more detail by fluorescence and NIR spectroscopy analyses. PSII maximum quantum yield ( $\mathrm{Fv} / \mathrm{Fm}$ ) in dark-adapted plants was not altered by the mutations (Table 1$)$. However, when plants were exposed to sub-saturating light conditions $\left(330 \mu \mathrm{mol}\right.$ photons $\left.\mathrm{m}^{-2} \mathrm{~s}^{-1}\right)$ both $n d u f a 5$ and ndufb10 showed a higher yield for both PSI (Figure 5A) and PSII (Figure 5B), indicative of a higher electron transport rate. At the level of PSI, the higher yield was attributable to a lower donor side limitation (YND) while acceptor side limitation (YNA) was neglectable in WT as in mutant plants (Figure 5C-D). The lower PSI donor side limitation is consistent with a higher rates of electron transport to PSI and this is consistent with a less reduced quinone $A\left(Q_{A}\right)$ in the mutants than in the WT, as estimated by 1-qL (Figure $5 E$ ). After actinic light was switched off, the estimated maximal quantum yield of PSI recovered to the same level in WT and mutants, whereas the recovery of PSII maximal yield and oxidation of $Q_{A}$ was faster in the mutants. NPQ in ndufa5 and ndufb10 was activated as in WT plants but after a few minutes of illumination, it showed a partial relaxation in mutants (figure 5F).

The same analyses showed similar results upon exposure to dim light $\left(50 \mu \mathrm{mol}\right.$ photons $\left.\mathrm{m}^{-2} \mathrm{~s}^{-1}\right)$, corresponding to the illumination in the growth chamber (Figure S5). If plants were exposed to $2000 \mu \mathrm{mol}$ photons $\mathrm{m}^{-2} \mathrm{~s}^{-1}$, a light intensity completely saturating photosynthetic capacity of the plants, WT and mutants showed instead no significant differences (Figure S6). 

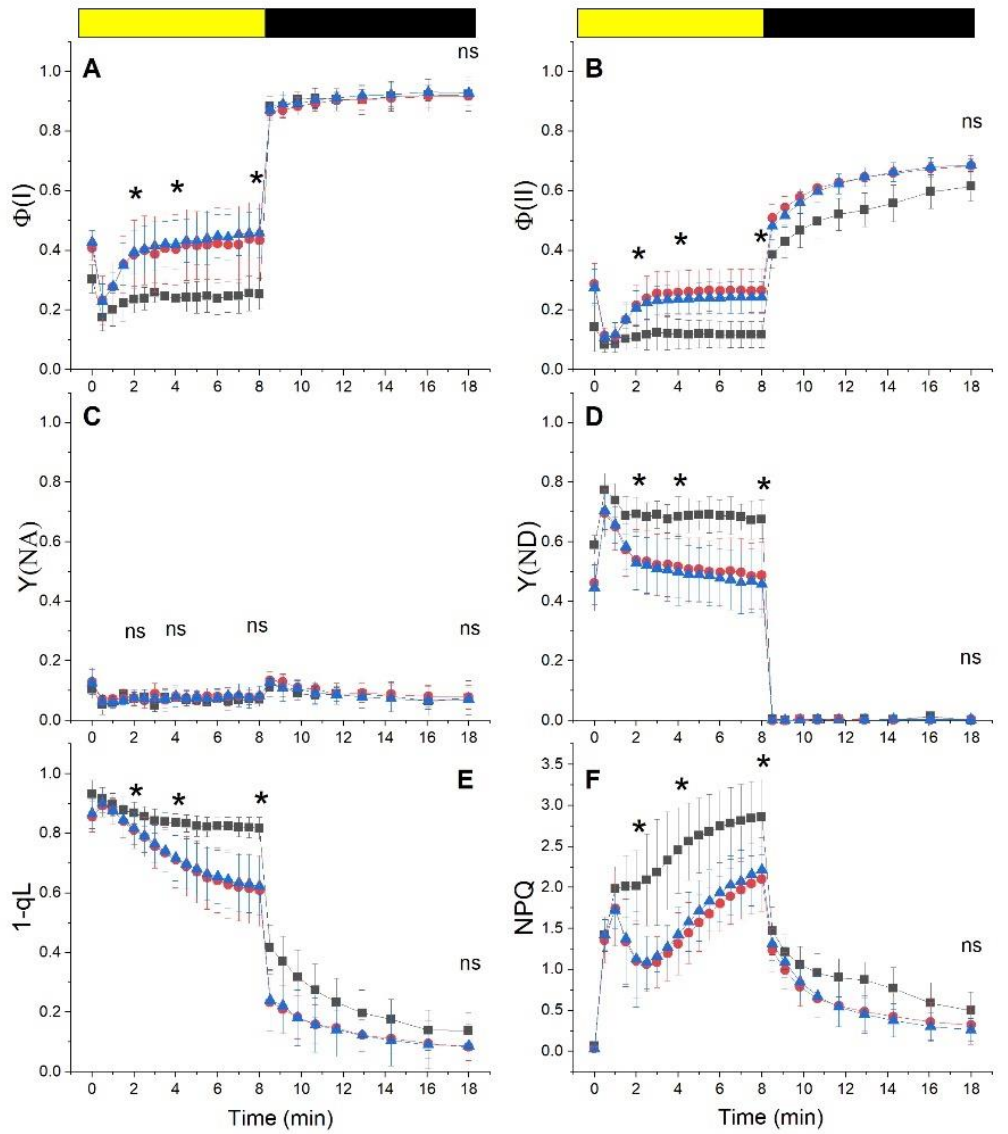

Figure 5. Alterations in Photosystem functionality in $\mathrm{Cl}$ mutants. The yield of $P S I(\Phi(I), A), P S I I(\Phi(I)), B)$. PSI acceptor side limitation (Y(NA), C), PSI donor side limitation (Y(ND), D). PQ redox state (1-qL; E) and nonphotochemical quenching (NPQ; F) were measured with Dual PAM 100 in plants exposed to $330 \mu \mathrm{mol}$ photons $\mathrm{m}^{-2} \mathrm{~s}^{-1}$ of actinic light intensity. Yellow / black bar indicates when actinic light was on / off respectively. WT, ndufb10 and ndufa5 KO are shown respectively with black squares, red circles and blue triangles. Data are shown as average $\pm S D(n>4)$. Asterisks indicate statistically significant differences from WT plants (one-way ANOVA, $n>5, p<0.01$ ) after 2,4 and 8 minutes of illumination and one after 10 minutes in the dark; ns indicates when eventual differences are not statically significant.

The impact of $\mathrm{Cl}$ mutations on photosynthetic electron transport was further investigated by measuring electrochromic shift (ECS) caused by the generation of transmembrane potential at the level of the thylakoid membranes (Witt, 1979; Bailleul et al., 2010). The total ECS signal (ECSt), a proxy of the total proton motive force (pmf) generated, was found to be similar in WT and ndufa5 and ndufb10 mutants over a range of actinic light intensities of different duration (Figure 6A).

ECS relaxation kinetics measured after the light was switched off after 300 seconds of illumination, however, indicated an altered partition between the electric and $\mathrm{pH}$ component of the transmembrane potential (Figure 6B) (Cruz et al., 2001). It is interesting to point out that this difference emerged as a consequence of the illumination since it became detectable only if plants were exposed to light for more than 120 seconds (Figure $6 \mathrm{~B}$ and Figure $\mathrm{S7}$ ). This suggests that the alterations in pmf partitioning emerged as a result of modifications in the photosynthetic activity (Avenson et al., 2005; Wang and Shikanai, 2019). This difference between genotypes was again light intensity-dependent and using a stronger, fully saturating, illumination (1000 $\mu \mathrm{mol}$ photons $\mathrm{m}^{-2} \mathrm{~s}^{-1}$ ) mutants were indistinguishable from WT (Figure S8). 

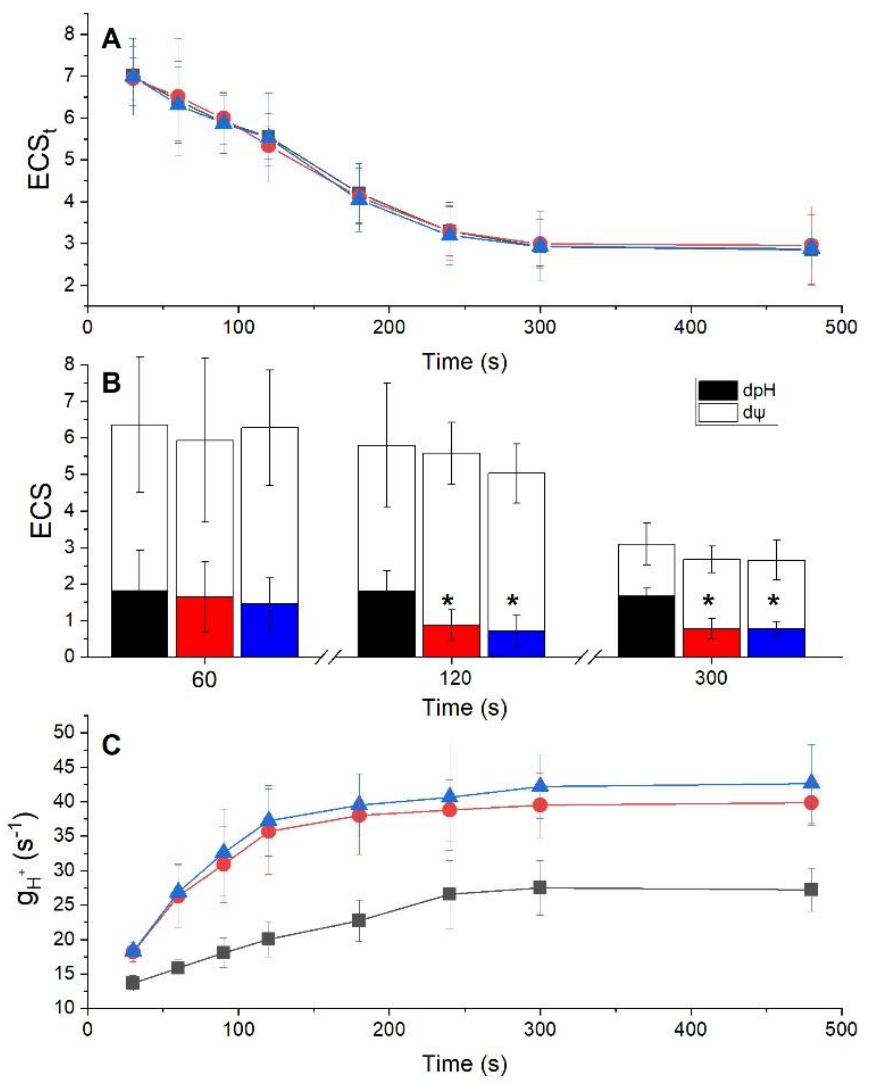

Figure 6. Impact of $\mathrm{Cl}$ inactivation on photosynthetic electron transport and proton motive force. A) Total electrochromic signal $\left(E C S_{t}\right)$ generated by illumination with sub-saturating light $\left(300 \mu \mathrm{mol}\right.$ photons $\left.\mathrm{m}^{-2} \mathrm{~s}^{-1}\right)$ at different intensity. $E C S_{t}$ was quantified as $\left(E_{C S} S_{20}-E C S_{546}\right)$ / PSI Charge Separation and indicative of the proton motive force (pmf) generated. WT, ndufb10 and ndufa5 KO are shown respectively in black, red and blue. Average $\pm S D(n \geq 5)$ is reported. B) quantification of total pmf as well as its partition in different components. $\Delta \mathrm{pH}$ is shown in black, red and blue for $\mathrm{WT}$, ndufb10 and $n d u f a 5 \mathrm{KO}$ respectively. The electric component $(\Delta \Psi)$ in shown in white. Averages $\pm S D(n \geq 5)$ are reported and asterisks indicate statistically significant differences (one-way ANOVA, $n>5, p<0.01$ ). D) $g_{H}{ }^{+}$is the proton conductivity of protons across the thylakoid membrane and it reflects the activity of ATPase. This was measured after exposing plants to light with different duration., WT, ndufb10 and ndufa5 $\mathrm{KO}$ are shown respectively as black squares, red circles and blue triangles.

To assess the impact of proton translocation, conductivity $\left(\mathrm{g}_{H^{+}}{ }^{+}\right.$from ATPase complex was estimated from the decay of ECS signal after the light was switched off. In both ndufa5 and ndufb10 the ECS decay kinetics were faster than WT, indicating that proton conductivity due to ATPase was higher (Figure S9). Monitoring of $g_{\mathrm{H}^{+}}$ using actinic illumination of different duration (between 30 and 480 seconds) showed that $g_{\mathrm{H}^{+}}$in WT plants increased with the duration of the illumination reaching a steady state after approx. five minutes, consistently with a progressive activation of ATPase (Figure 6C), following a modulation of chloroplast ATPase activity by the sensing of stromal metabolic status during steady-state photosynthesis (Takizawa et al., 2008; Kohzuma et al., 2013). Interestingly, in ndufa5 and ndufb10 mutants the $g_{H}+$ was higher but also more rapidly activated and it reached the maximal activity after about 120 seconds of illumination instead of the 300 seconds required by WT plants (Figure 6C).

Lumenal pH is a major signal for regulation of photosynthesis and its decrease under strong illumination is known to activate protective mechanisms such as heat dissipation of excess energy (non-photochemical 
quenching, NPQ) and the xanthophyll cycle (Li et al., 2009). Low lumenal $\mathrm{pH}$ is also known to inhibit cytochrome $b_{6} f$ activity to avoid over-reduction of PSI, a mechanism known as photosynthetic control (Nishio and Whitmarsh, 1993). When photosynthetic control is active, the electron transport rate from plastoquinol $\left(\mathrm{PQH}_{2}\right)$ is slower, to reduce possibilities of PSI over-reduction. The impact of $\mathrm{Cl}$ mutations on Cyt $b_{6} f$ activity was assessed by monitoring Cytochrome $f(\mathrm{Cyt} f$ ) oxidation state from an absorption signal at $554 \mathrm{~nm}$ (Figure $7 \mathrm{~A}$, see methods for details). The oxidation state in illuminated samples can be estimated by comparing the signal with plants treated with PSII and Cyt $b_{6} f$ inhibitors DCMU and DBIMB where electron transport from $\mathrm{PQ}$ is blocked and thus Cyt $\mathrm{f}$ is fully oxidized. In ndufb10 and ndufa5 illuminated with sub-saturating light (300 $\mu \mathrm{mol}$ photons $\mathrm{m}^{-2} \mathrm{~s}^{-1}$ ) Cyt $\mathrm{f}$ is less oxidised than in WT plants (Figure 7B). When the light was switched off Cyt $\mathrm{f}$ reduction in mutants was also faster than in WT (Figure $7 \mathrm{C}$ ), thus suggesting that in these plants electron transport from $\mathrm{PQH}_{2}$ is faster (Stiehl and Witt, 1969).
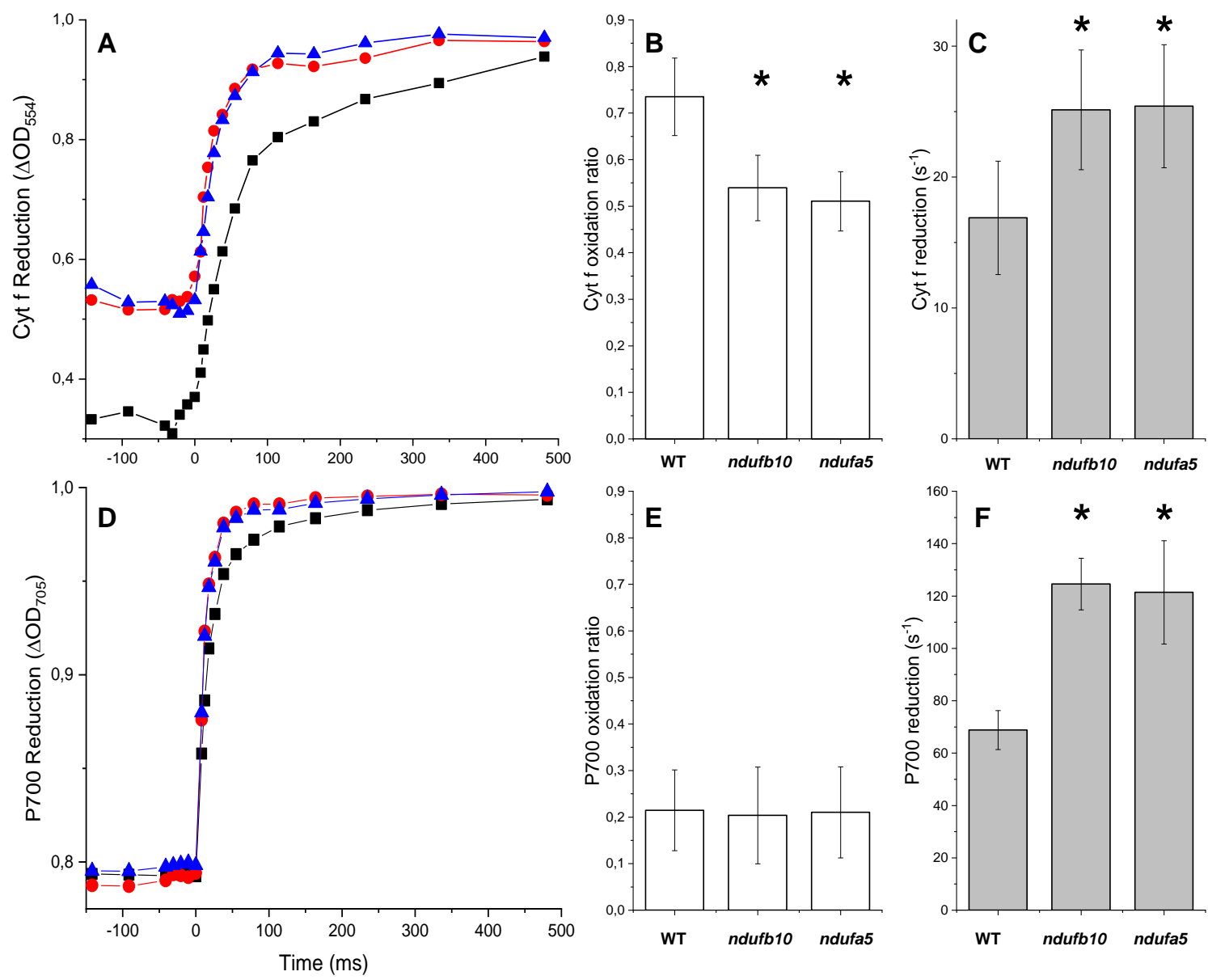

Figure 7. Cytochrome $\mathrm{f}$ and PSI oxidation. A) Cytochrome $\mathrm{f}$ oxidation monitored from $\triangle \mathrm{OD}_{554}$ in dark-adapted plants subjected to constant illumination $\left(300 \mu \mathrm{mol}\right.$ photons $\left.\mathrm{m}^{-2} \mathrm{~s}^{-1}\right)$ for $480 \mathrm{~s}$ before the light was switched off. B) Oxidation state is expressed as the ratio between Cyt $f$ signals at the end of illumination and the maximal oxidation levels obtained by addition of DCMU/DBMIB to obtain complete oxidation. Reported values are average $\pm S D(n \geq 4)$. C) Cyt $f$ reduction rate in the different genotypes after $480 \mathrm{~s}$ actinic light exposure, quantified from half-time reduction. WT, ndufb10 and ndufa $5 \mathrm{KO}$ are shown respectively as black squares, red circles and blue triangles. Curves shown are the average of 4 independent measurements. For $A$ and $C$ asterisks indicate statistically significant differences (one-way ANOVA, $n>5, p<0.01$ ). D) PSI oxidation monitored from $\triangle \mathrm{OD}_{705}$ in dark-adapted plants exposed to constant illumination $\left(300 \mu \mathrm{mol}\right.$ photons $\left.\mathrm{m}^{-2} \mathrm{~s}^{-1}\right)$ for $480 \mathrm{~s}$. B) P700 oxidized fraction is expressed as the ratio between $\mathrm{P} 700^{+}$signals at the end of illumination and the maximal oxidation levels obtained by addition of DCMU and DBMIB to block the PSI re-reduction. Reported values are 
average $\pm S D(n \geq 4)$. F) $\mathrm{P} 700^{+}$reduction rate estimated from half-time reduction after $480 \mathrm{~s}$ actinic light exposure in the different genotypes. WT, ndufb 10 and ndufa $5 \mathrm{KO}$ are shown respectively as black squares, red circles and blue triangles. For $F$ asterisks indicate statistically significant differences (one-way ANOVA, $n>5, p$ $<0.01)$.

In the same measuring conditions, the impact on PSI was monitored from P700 oxidation state using a similar spectrophotometric approach, monitoring a differential absorption signal at $705 \mathrm{~nm}$ ( $\triangle \mathrm{OD}_{705}$, Figure $7 \mathrm{D}$ ). $\mathrm{Cl}$ mutants showed similar P700 oxidation level compared to WT plants at steady-state illumination (Figure 7E). However, when the light was switched off the rate of P700 reduction was faster in the mutants, suggesting that electrons flux toward P700 was more rapid (Figure 7F) consistent with a higher $\mathrm{PQH}_{2}$ oxidation rate.

\section{Discussion}

Inactivation of Complex I by targeting two different subunits yielded the same effects.

In this work, independent $\mathrm{KO}$ lines targeting two subunits of $\mathrm{Cl}$ were generated and verified to have the insertion of the resistance cassette in the expected genome position and to lose the mRNA expression (Figure 1 and Figure S1). ndufa5 KO show complete depletion of $\mathrm{Cl}$ activity in BN-PAGE (Figure 3B) and it did not accumulate NAD9 (Figure 3A), a core subunit of the $Q$ module that is directly involved in the transfer of electrons to the ubiquinone which is required for the complex functionality (Massoz et al., 2013). This is consistent with previous results showing that NDUFA5 interacts with NAD7 and NAD9 to form an 80 KDa subcomplex that successively is integrated into the $\mathrm{Cl}$ (Ligas et al., 2019). The second targeted subunit, NDUFB10, is instead integrated later during $\mathrm{Cl}$ assembly and, in its absence, there is the formation of an incomplete $\mathrm{Cl}$ of $800 \mathrm{kDa}$ including both the $\mathrm{N}$ and $\mathrm{Q}$ modules but missing the proton pumping module and thus the biological activity (Barbieri et al., 2011). Despite this partial retention of some subunits (Figure 3), both mutants have inactive $\mathrm{Cl}$ as shown by the insensitivity of oxygen consumption to the specific inhibitor rotenone (Figure 4B). In both lines, oxygen consumption in the dark is enhanced compared to WT plants. This can be explained by the re-organization of respiratory apparatus with increased CII and CIII content and a strong over-accumulation of AOX detectable both at the protein and activity level (Figure 3-4). Such reorganization of respiratory complexes allows compensating for the absence of $\mathrm{Cl}$ activity, that in WT accounts for approx. $40 \%$ of $\mathrm{O}_{2}$ consumption rate in the dark (Figure 4B), reaching $\mathrm{O}_{2}$ evolution activities even higher than WT (Figure 4A). Such an enhanced oxygen consumption activity, however, is not expected to translate in a full recovery of the capacity of ATP biosynthesis since CII and alternative pathways like AOX do not contribute to the generation of transmembrane potential as $\mathrm{Cl}$ (Vanlerberghe et al., 2020).

Alterations in respiratory complexes were also observed in $\mathrm{Cl}$ mutants from Arabidopsis (Fromm et al., 2016b) and Nicotiana (Vidal et al., 2007) that also showed increased AOX accumulation and higher oxygen consumption in the dark. In Arabidopsis, it was shown that increased oxygen consumption in the dark is a distinctive feature of complete $\mathrm{Cl} \mathrm{KOs,} \mathrm{while} \mathrm{this} \mathrm{is} \mathrm{not} \mathrm{observed} \mathrm{in} \mathrm{Cl}$ partial mutants or KD lines (Kühn et al., 2015). Based on this observation, the increase in $\mathrm{O}_{2}$ consumption observed in P. patens ndufa5 and ndufb10 $\mathrm{KO}$ is a further confirmation that both lines have fully inactivated $\mathrm{Cl}$.

It is remarkable to observe that $n d u f a 5$ and $n d u f b 10 \mathrm{KO}$ show the same phenotypic differences with respect to WT in all analyses performed (Figure 2-8), even if the targeted genes were different. This similarity strongly suggests that plants responses observed are attributable to the lack of complex I activity, while the impact of specific subunits is minor, at least on the phenotypes analysed. 
Impact of respiration on photosynthesis adapted during evolution.

All $P$. patens cells in various developmental stages contain chloroplasts and are photosynthetically active even if at different levels (Sakakibara et al., 2003). Here plants were analysed 10 days after inoculum on a mineral media containing no reduced carbon and were mainly composed by chloronema, a developmental stage containing phototrophic cells particularly rich in chloroplasts (Furt et al., 2012). The combined choice of the model organism and developmental stage, thus, should allow assessing the impact of respiration on photosynthesis without the influence of heterotrophic tissues like roots that are expected to be largely impacted by the lack of respiration. Despite the lack of heterotrophic cells, P. patens plants depleted in Complex I present a strong phenotype with a drastically impaired growth (Figure 2), demonstrating that respiration plays a major role in photosynthetically active cells in plants.

Plants exposed to 24 hours continuous light did not show any growth recovery suggesting that the impact of respiration is also not limited to sustaining metabolism during the night (Figure 2 and Figure S2). Even more strikingly, while WT plants exposed to continuous illumination show faster growth (Figure S2), this is not the case for $\mathrm{Cl}$ mutants that are not able to exploit the extra light energy available. This show that inactivation of respiration directly impacts photosynthetic metabolism in $P$. patens plants and their ability to use light energy for growth.

The phenotypes of $\mathrm{Cl}$ mutants in $\mathrm{P}$. patens and Arabidopsis shows many similarities, such as the strong impact on growth and increased oxygen consumption activity, as the result of a re-organization of respiratory apparatus and an increased AOX content which ultimately lead to an increase of the electron flow through the alternative pathway with the purpose to sustain cellular ATP demand (Figure 3-4) (Kühn et al., 2015; Fromm et al., 2016a). This suggests that those phenotypes observed in Arabidopsis (Kühn et al., 2015) or tobacco (Vidal et al., 2007) are also attributable to effects on photosynthetic active cells, beyond the role in supporting metabolism during the night or in heterotrophic cells like roots.

$\mathrm{Cl}$ mutants in the green alga Chlamydomonas reinhardtii, instead, have a growth rate close to WT in photoautotrophy and only show a decrease in duplication rate in heterotrophic conditions (Salinas et al., 2014; Larosa et al., 2018). Complex I mutants in Chlamydomonas also do not experience a reorganization of respiratory apparatus and showed a reduced oxygen consumption activity (Barbieri et al., 2011; Massoz et al., 2013; Larosa et al., 2018). Available information thus suggests that in plants respiration has a larger influence in photosynthetic metabolism than in Chlamydomonas reinhardtii.

While it is not possible to drive general conclusions on a highly diverse group such as eukaryotic algae-based only on information from a few species, these examples suggest the interaction between photosynthesis and respiration changed during evolution. Plants rely on photo-autotrophy and normally cannot complete their developmental cycle in the dark even if reduced carbon is supplied (Neff et al., 2000). The fact that obligate photo-autotrophic organisms rely more on respiration seems counterintuitive, but it can be explained considering that in these organisms mitochondrial respiration activity gradually adapted to work together with photosynthesis, optimizing the metabolite fluxes between organelles (Shameer et al., 2019). Respiration thus could gradually assume a major role in essential processes for photosynthesis such as redox balance and photorespiration, becoming itself essential for cells.

On the other hand, Chlamydomonas can growth in both autotrophic and heterotrophic conditions depending on the presence of carbon sources (Harris, 2001), an adaptation to a growing environment where light is not always present and cells must rely on other sources of energy to support their metabolism (Yang et al., 2015). Chlamydomonas cells can be exposed even to anaerobic conditions when it can activate fermentative 
metabolism and hydrogen production (Ghirardi et al., 2007; Grossman et al., 2011; Grechanik et al., 2020). In those anaerobic conditions, oxygen is absent and thus respiration is fully inactivated but still cells can perform photosynthesis (Godaux et al., 2015) that must thus be independent of respiratory activity. In organisms with such large metabolic flexibility and particularly if they are exposed to anaerobic conditions, respiration while important cannot assume an essential role in the photosynthesis, explaining why they are less impacted by a inactivation.

Complex I Deficiency alters chloroplast ATP synthase activity and photosynthetic control of electron transport Plants depleted in $\mathrm{Cl}$ did not show any major alteration in the composition of the major photosynthetic pigments (Table 1) and complexes, PSI, PSII, Cyt b6f with only a slight increase in Chloroplast ATPase (Figure S4). Despite these similarities when plants are exposed to sub-saturating illumination ( $300 \mu \mathrm{mol}$ photons $\mathrm{m}^{-2}$ $\mathrm{s}^{-1}$ and below) show several differences in photosynthetic functionality. Both PSI and PSII show a higher yield in mutants, suggesting a lower saturation level in illuminated plants and thus higher transport rate. $\mathrm{Cl}$ mutants also show increased protein conductivity across the thylakoids membrane that, combined with an equivalent proton motive force, is again consistent with a higher electron transport rate.

The higher $g_{H}+$ observed can be attributed to a higher ATPase activity. Chloroplast ATPase is in fact slightly over-accumulated in the mutants but it is also activated faster during the dark to light transitions in the mutants (Figure 6C and Figure S9) than in WT. ATPase activity is also inhibited by the depletion of inorganic phosphate (Pi) or ADP pool through metabolic feedback (Takizawa et al., 2008) and the higher activity in $\mathrm{Cl}$ mutants could also be the result of a less effective metabolic control. The higher activity of chloroplast ATPase would thus be a response to satisfy an increased demand for ATP, compensating for a reduced contribution from mitochondrial respiration.

The higher ATPase activity causes a faster translocation of protons in the stroma and an increase in the lumenal $\mathrm{pH}$ (Figure 6B), in turn, affecting photosynthesis regulatory mechanisms modulated by lumen acidification. The WT and mutant lines accumulated similar levels of NPQ activators PsbS or LHCSR (Figure S4) and, consistently, the maximal NPQ capacity is equivalent in all genotypes (Figure S6F). However, mutants exposed to sub-saturating illumination show a relaxation of NPQ after a few minutes (Figure 5F) that can be explained by a reduction of $\triangle \mathrm{pH}$ across the thylakoids membrane ((Joliot and Finazzi, 2010), Figure 6B-C).

An altered lumen acidification is also expected to affect photosynthetic control, the modulation of $\mathrm{PQH}_{2}$ oxidation at the Cyt $b 6 f$. Mutants exposed to sub saturating illumination indeed showed a faster rate of Cyt $f$ reduction (Figure $8 \mathrm{C}$ ), suggesting a higher electron transport activity and a lower photosynthetic control. This hypothesis is consistent with several other differences observed such as the higher efficiency in both photosystems (Figure 5A-B and Figure S5A-B), a less pronounced PSII acceptor limitation (1-qL) (Figure 5E) and PSI donor limitation (YND) (Figure 5D and Figure S5D) compared to WT. PSI also shows faster reduction kinetics (Figure 8F). All the differences observed between the WT and mutants, summarized in Figure S10, can be explained with a decreased photosynthetic control and thus a higher Cyt $b_{6} f$ activity, thus increasing the rate of transport of electrons from PQ to PSI as the result of higher ATPase activity and higher lumenal pH (Takizawa et al., 2007; Takizawa et al., 2008).

It is interesting to observe that when light is in strong excess $\left(1000-2000 \mu \mathrm{mol} \mathrm{m}{ }^{-2} \mathrm{~s}^{-1}\right.$, Figure S6 and Figure S8), thus 25-50 times higher than the illumination used for plants growth, the mutants become indistinguishable from WT. This observation suggests that with a very strong illumination the eventual differences in ATPase conductivity are uninfluential, an expected behaviour if in these conditions the 
downstream metabolic reactions became strongly saturated. This further confirms the conclusion that photosynthetic apparatus is highly similar in WT and Cl mutants and that the phenotypes observed in the latter are due to the depletion of respiration that affects the regulation of photosynthesis within the chloroplast. This could be explained by idea that ATP pools in chloroplast, mitochondria and cytosol are exchangeable, if not directly through transport of reduced molecules that are used for ATP biosynthesis (Shameer et al., 2019) and thus if ATP biosynthesis is reduced in the mitochondria because of $\mathrm{Cl}$ inactivation it causes indirect effects on photosynthetic activity.

\section{Acknowledgments.}

We thank Dr. Etienne Meyer (Institute of Plant Physiology; the Martin-Luther-University, Halle-Wittemberg) for providing the NAD9 antibody and Prof. Hans-Peter Braun (Institute of Plant Genetics; Leibniz University, Hannover) for the SDH1-1, $\alpha$-MPP, COX2 and ATPase $\beta$-subunit antibodies.

\section{Materials and Methods}

Plant material and growth. P. patens.

P. patens (Gransden) Wild-Type (WT), ndufb10 and ndufa5 KO lines were cultivated in the protonemal phase by vegetative propagation on $\mathrm{PpNH}_{4}$ medium (Ashton et al., 1979) and grown under standard conditions: $24^{\circ} \mathrm{C}$, long photoperiod (16:8 light: dark) with $50 \mu \mathrm{mol}$ photons $\mathrm{m}^{-2} \mathrm{~s}^{-1}$. Physiological and biochemical characterizations were performed on 10 day-old tissue cultivated in $\mathrm{PpNO}_{3}$ medium (Ashton et al., 1979). The growth rate in all the media and light conditions was evaluated starting from protonema colonies of $2 \mathrm{~mm}$ in diameter followed for 21 days. Colony size was measured as in Storti et al., (2019). In brief, high-quality images (600 ppi) were acquired using a Konica Minolta Bizhub C280 scanner. Images were analysed with FIJI (https://fiji.sc/) using the 'threshold colour' plugin to subtract the plate background. Colony size was calculated from the integrated density (area $x$ mean density). This strategy was chosen to take into account the development from 2D (chloronema and caulonema) to 3D structures (gametophore and rhizoids) of moss colonies which are lost considering only the area.

\section{Moss transformation and mutant selection.}

The ndufb10 and ndufa5 KO constructs were employed to mutate the Ndufb10 gene and Ndufa5 gene respectively (Figure S1). The transformation was performed through protoplast DNA uptake as described in Alboresi et al. (2010). 6-day old protonema cells growth in $\mathrm{PPNH}_{4}$ medium were treated with fungal driselase (Sigma-Aldrich) to break the cell wall. Resulting protoplasts were filtered with $100 \mu \mathrm{m}$ micro cloth. Protoplasts were washed and resuspended in PEG-4000-containing solution, mixed with digested linear DNA from KO constructs $(20 \mu \mathrm{g})$ and exposed to heat shock $\left(5 \mathrm{~min}\right.$ at $\left.45^{\circ} \mathrm{C}\right)$ to open cell membrane. After 1 day of recovery, protoplasts were first immersed in a top layer solution and plated on agarified medium added with mannitol to prevent their lysis. After 7 days, recovered cells were moved to a new plate with antibiotics for transformants selection. The selection was repeated twice. Resulting transformants were homogenized using $3 \mathrm{~mm}$ zirconium glass beads (Sigma-Aldrich), and genomic DNA (gDNA) was isolated according to a rapid extraction protocol (Edwards et al., 1991) with minor modification. PCR amplifications of recombination cassette were performed on extracted gDNA (Table S1; Fig. 1, Fig. S1). To confirm that ndufb10 and ndufa5 KO lines were lacking target gene expression Reverse-Transcriptase PCR (RT-PCR) was performed on cDNA (RevertAid Reverse Transcriptase; Thermo Scientific) synthesized after RNA extraction. 


\section{Western blot analysis.}

Total protein extracts were obtained by pestled protonema tissue in sample buffer ( $50 \mathrm{mM}$ TRIS pH 6.8, 100 mM DTT, 2\% SDS and 10\% glycerol). Samples total chlorophyll was quantified, and every well was loaded accordingly to the quantification. After SDS-PAGE, proteins were transferred to a nitrocellulose membrane (Pall Corporation). Membranes were hybridized with specific primary antibodies: anti-PsaA, Agrisera, catalogue number AS06172; anti-Cyt $f$, Agrisera, catalogue number AS06119; anti- $\gamma$ ATPase, Agrisera, catalogue number AS08312, anti-AOX1/2, Agrisera, catalogue number AS04054; custom made anti-NAD9 (Schimmeyer et al., 2016); custom made anti-SDH1-1 (Complex II), anti- $\alpha$-MPP (Complex III), anti-COX2 (Complex IV), anti- $\beta$ subunit (Complex V) (Peters et al., 2012) and custom made anti-D2, anti-PSBS and antiLHCSR (Storti et al., 2019). After hybridization, signals were detected with alkaline phosphatase-conjugated antibody (Sigma Aldrich).

\section{Crude membrane extracts preparation.}

Crude membrane extracts were prepared as in Pineau et al., (2008) with minor modifications. Approximately $300 \mathrm{mg}$ of fresh or frozen $\left(-80^{\circ} \mathrm{C}\right)$ protonema grown in PPNO3 for 10 days were homogenized in $2 \mathrm{ml}$ of $75 \mathrm{mMMOPS}-\mathrm{KOH}, \mathrm{pH} 7.6,0.6 \mathrm{Msucrose}, 4 \mathrm{mM}$ EDTA, $0.2 \%$ polyvinylpyrrolidone $40,8 \mathrm{mM}$ cysteine, $0.2 \%$ bovine serum albumin using a plant Potter glass tissue grinder pound at $0{ }^{\circ} \mathrm{C}$. The homogenate was filtrated across one layer of micro cloth with $20 \mu \mathrm{m}$ pores and centrifuged at $4^{\circ} \mathrm{C}$ at $1300 \mathrm{~g}$ for $4 \mathrm{~min}$. The supernatant was collected and centrifuged again at 22,000 g for $20 \mathrm{~min}$. The resultant pellet, which contained most of the thylakoid and mitochondria membranes, was resuspended in $200 \mu \mathrm{L}$ of $10 \mathrm{mM} \mathrm{MOPS}-\mathrm{KOH}, \mathrm{pH} 7.2,0.3 \mathrm{M}$ sucrose. The protein concentration on crude membrane extracts was quantified using the BCA protein assay.

\section{Blue native protein electrophoresis (BN-PAGE).}

Gels were cast in $8 \times 10 \mathrm{~cm}$ plates using the buffer described by Kügler et al., (1997) with an acrylamide gradient of $4-12 \%$ in the running gel and $4 \%$ acrylamide in the stacking gel. A volume of crude membrane extracts corresponding to $100 \mathrm{mg}$ of proteins wash washed with three volumes of $\mathrm{H} 2 \mathrm{O}$ Milli- ${ }^{\circledR}$ and centrifuged at $4{ }^{\circ} \mathrm{C}, 21,470 \mathrm{~g}$ for $20 \mathrm{~min}$. The pellet was resuspended in $20 \mu \mathrm{L}$ of ACA buffer $1 \times(50 \mathrm{mM}$ BisTris, pH 7.0; 750 mM aminocaproic acid; 1 mM EDTA) Järvi et al., (2011). For protein solubilization $20 \mu \mathrm{L}$ of $\beta$ dodecyl maltoside ( $\beta$-DM) $2 \%(\mathrm{w} / \mathrm{v})$ prepared in ACA buffer were added to the tube, to reach a final volume of $40 \mu \mathrm{L}$, reaching $\beta$-DM $1 \%$ in ACA buffer. Each tube was vortexed for 30 seconds, kept on ice for 5 min and centrifuged at $4^{\circ} \mathrm{C}, 22,000 \mathrm{~g}$ for $8 \mathrm{~min}$. The supernatant was supplemented with $4 \mu \mathrm{L}$ of Coomassie Blue $5 \%$ solution (20 mM Bis-Tris, 500 mM aminocaproic acid, Coomassie Blue G-250 5 \% (w/v)). Anode and cathode buffers were the same used by Järvi et al. (2011) for BN gel; the cathode buffer was supplemented with Coomassie Blue G-250 $0.02 \%$ (w/v). The gel was run at $75 \mathrm{~V}$ for 30 minutes. Then, the cathode buffer was replaced with fresh cathode buffer without Coomassie Blue and the gel was run at $100 \mathrm{~V}$ for $30 \mathrm{~min}$, at $125 \mathrm{~V}$ for $30 \mathrm{~min}$, at $150 \mathrm{~V}$ for $60 \mathrm{~min}$, at $175 \mathrm{~V}$ for $30 \mathrm{~min}$ and at $200 \mathrm{~V}$ for $60 \mathrm{~min}$. The total running time was about 4 hours.

Determination of NAH dehydrogenase in-gel activity.

After BN-PAGE, the NADH dehydrogenase activity of $\mathrm{Cl}$ was revealed by incubation of the gel in the presence of $1 \mathrm{mM}$ nitro blue tetrazolium (NBT) and $0.2 \mathrm{mM}$ NADH in $50 \mathrm{mM}$ potassium phosphate buffer ( $\mathrm{pH} 7.0$ ) (Barbieri et al., 2011).

\section{Oxygen consumption and oxygen evolution}


Oxygen consumption and evolution were evaluated as in Storti et al. (2020) with a Clark-type $\mathrm{O}_{2}$ electrode (Hansatech, King's Lynn, UK). In brief, two protonema disks of about $1 \mathrm{~cm}$ of diameter coming from 10 days old plates were introduced in the measurement chamber filled with $2 \mathrm{~mL}$ of a solution containing $\mathrm{NaCO}_{3} 0.1$ $\mathrm{mM}$ maintained at $23^{\circ} \mathrm{C}$. After ten minutes in the dark (respiratory rate), the light was turned on and the oxygen variation was recorded for other ten minutes (photosynthetic rate). $\mathrm{O}_{2}$ consumption and evolution rates were normalized to the total $\mathrm{Chl}$ content of each sample. Chl content was evaluated after extraction with $80 \%$ acetone (Porra et al., 1989). Inhibitors employed for respiratory analysis were $50 \mu \mathrm{M}$ rotenone (Complex I), $1 \mathrm{mM} \mathrm{KCN} \mathrm{(Complex} \mathrm{IV)} \mathrm{and} 2 \mathrm{mM} \mathrm{SHAM} \mathrm{(AOX).} \mathrm{For} \mathrm{inhibitor} \mathrm{treatments,} \mathrm{protonema} \mathrm{tissue} \mathrm{was} \mathrm{incubated}$ 30 minutes in the dark in medium supplemented with the inhibitor. Inhibitors were also added at the measuring chamber during oxygen consumption evaluation.

\section{Pigment analysis}

10 days old protonemal cells were broken with a plastic grinder and pigments were extracted with 80\% acetone. Whole-plant extracts in acetone were fitted with those of individual purified pigments to calculate Chla/b and Chl/carotenoid (Chl/Car) ratios (Croce et al., 2002).

\section{Spectroscopic analyses.}

In vivo chlorophyll fluorescence and Near InfraRed (NIR) absorption analyses were performed at room temperature with a Dual-PAM 100 system (Walz) on protonema grown for 10 days in $\mathrm{PpNO}_{3}$ in WT and mutant lines. Before the analysis, the plants were adapted in the dark for $40 \mathrm{~min}$, and the $F_{v} / F_{m}$ parameter was calculated as $\left(\mathrm{F}_{\mathrm{m}}-\mathrm{F}_{\mathrm{o}}\right) / \mathrm{F}_{\mathrm{m}}$. Induction curves were obtained setting actinic red light at (approx.) 50, 330 or 2000 $\mu \mathrm{mol}$ photons $\mathrm{m}^{-2} \mathrm{~s}^{-1}$, and photosynthetic parameters were recorded every $30 \mathrm{~s}$. At each step, the photosynthetic parameters were calculated as follows: $\Phi(I I)$ as $\left(F_{m}{ }^{\prime}-F_{o}\right) / F_{m}{ }^{\prime}$, $q L$ as $\left(F_{m}{ }^{\prime}-F\right) /\left(F_{m}{ }^{\prime}-F_{o}{ }^{\prime}\right) \times F_{o}{ }^{\prime} / F$ and $N P Q$ as $\left(F_{m}-F_{m}{ }^{\prime}\right) / F_{m}{ }^{\prime}, \Phi(I)$ as $1-Y(N D)-Y(N A) ; Y(N A)$ as $\left(P_{m}-P_{m}{ }^{\prime}\right) / P_{m} ; Y(N D)$ as $\left(P-P_{o} / P_{m}\right)$ (Klughammer and Schreiber, 1994). Electrochromic shift (ECS) spectra were recorded with a JTS-10 system (Biologic) in plants that were dark acclimated for $40 \mathrm{~min}$ and imbibed with $20 \mathrm{mM}$ HEPES, pH 7.5. and $10 \mathrm{mM} \mathrm{KCl}$. For each measure, the background signal at $546 \mathrm{~nm}$ was subtracted from the $520 \mathrm{~nm}$ signal, in this way eliminating the contribution of scattering and cytochromes. Functional total Photosystems (PSs) quantification was performed by a single flash turnover using a xenon lamp. The light produced by xenon gas can induce PSI double charge separation, and thus PSI content could be overestimated by c. $40 \%$ but it does not affect the comparison of different samples (Gerotto et al., 2016). Moreover, samples were incubated with $20 \mu \mathrm{M}$ 3-(3,4dichlorophenyl)-1,1-dimethylurea (DCMU) and 4 mM HA (hydroxylamine) to calculate the contribution of PSI alone (Joliot et al., 2004). Total Electron Transport Rate (ETR) was measured with DIRK (dark-induced relaxation kinetic (Sacksteder and Kramer, 2000)) analysis as in Gerotto et al. (2016). Briefly, throughout 5 min of continuous illumination (at 350 or $940 \mu \mathrm{mol}$ photons $\mathrm{m}^{-2} \mathrm{~s}^{-1}, 630 \mathrm{~nm}$ LED) light was switched off at different times $(0.24,0.52,0.79,1.07,1.52,2.47,3.93,6.38,8.83,18.88,48.9,168.97,288.99 \mathrm{~s})$ for 20ms to follow fast relaxation of the ECS components (Slope in the Dark, SD). ETR was calculated as the ECS signal in light (SL) subtracted from the SD and normalized to the sample PSI content. At the end of the fifth min, the light was switched off to follow relaxation kinetics and evaluate the proton motive force (pmf) generated during light treatment as in Storti et al., (2020). The pmf was determined as the difference of the maximum signal at the light steady-state and minimum level of ECS in the dark and normalized to total charge separation PSI. The pmf portioning in $\Delta \Psi$ and $\Delta \mathrm{pH}$ was performed as in Baker et al., (2007). The ECS relaxation was followed for $30 \mathrm{~s}$ after light to dark transition and the ECS signal in this relaxed state was recorded. Difference between the

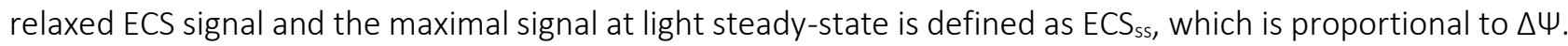
$\triangle \mathrm{pH}$ was calculated from the difference between the relaxed ECS signal and a minimum level of ECS in the dark. Proton conductance $\left(\mathrm{g}_{\mathrm{H}^{+}}\right)$was estimated by fitting the first $300 \mathrm{~ms}$ of the ECS decay curve with a first- 
order exponential decay kinetic as the inverse of the decay time constant as described earlier (Avenson et al., 2005). $\mathrm{g}_{\mathrm{H}^{+}}$was calculated after exposure to 30s, 60s, 90s, 120s, 180s, 240s, 300s and 480s of illumination (350 $\mu \mathrm{mol}$ photons $\left.\mathrm{m}^{-2} \mathrm{~s}^{-1}\right)$. P700 absorption kinetics were calculated from the absorption at $705 \mathrm{~nm}\left(\triangle_{\mathrm{OD}} 705\right)$ and following the re-reduction after plants were illuminated for $5 \mathrm{~min}$ at $350 \mu \mathrm{mol}$ photons $\mathrm{m}^{-2} \mathrm{~s}^{-1}$. Oxidized P700 was calculated by comparing the maximum signal from $\mathrm{P} 700^{+}$obtained before and after incubating plants with20 $\mu \mathrm{M}$ DCMU and $150 \mu \mathrm{M}$ 2,5-Dibromo-6-isopropyl-3-methyl-1,4-benzoquinone (DBIMB). P700 kinetic rate was calculation by relaxation time $\mathrm{t}_{1 / 2}$ of $\mathrm{P} 700^{+}$reduction after light was switched off. Cyt $f$ absorption was calculated as for $\mathrm{P} \mathrm{OO}^{+}$, except for the interference filter at $554 \mathrm{~nm}$. In this case, $546 \mathrm{~nm}$ and $573 \mathrm{~nm}$ were used as background and removed to $554 \mathrm{~nm}$ signal (Finazzi et al., 1997). Oxidation status and Cyt $f$ kinetic rate measurements were performed as for P700 measurements. 
References.

Alboresi A, Gerotto C, Giacometti GM, Bassi R, Morosinotto T (2010) Physcomitrella patens mutants affected on heat dissipation clarify the evolution of photoprotection mechanisms upon land colonization. Proc Natl Acad Sci U S A 107: 11128-33

Ashton NW, Grimsley NH, Cove DJ (1979) Analysis of gametophytic development in the moss, Physcomitrella patens, using auxin and cytokinin resistant mutants. Planta 144: 427-435

Avenson TJ, Cruz JA, Kanazawa A, Kramer DM (2005) Regulating the proton budget of higher plant photosynthesis. Proc Natl Acad Sci U S A 102: 9709-13

Bailleul B, Berne N, Murik O, Petroutsos D, Prihoda J, Tanaka A, Villanova V, Bligny R, Flori S, Falconet D, et al (2015) Energetic coupling between plastids and mitochondria drives CO2 assimilation in diatoms. Nature 524: 366-9

Bailleul B, Cardol P, Breyton C, Finazzi G (2010) Electrochromism: A useful probe to study algal photosynthesis. Photosynth Res 106: 179-189

BAKER NR, HARBINSON J, KRAMER DM (2007) Determining the limitations and regulation of photosynthetic energy transduction in leaves. Plant Cell Environ 30: 1107-1125

Barbieri MR, Larosa V, Nouet C, Subrahmanian N, Remacle C, Hamel PP (2011) A forward genetic screen identifies mutants deficient for mitochondrial complex I assembly in Chlamydomonas reinhardtii. Genetics 188: 349-58

Braun H-P, Binder S, Brennicke A, Eubel H, Fernie AR, Finkemeier I, Klodmann J, König A-C, Kühn K, Meyer E, et al (2014) The life of plant mitochondrial complex I. Mitochondrion 19 Pt B: 295-313

Cardol P, Gloire G, Havaux M, Remacle C, Matagne R, Franck F (2003) Photosynthesis and state transitions in mitochondrial mutants of Chlamydomonas reinhardtii affected in respiration. Plant Physiol 133: 201020

Cheung MCY, Ratcliffe GR, Sweetlove $\amalg$ (2015) A method of accounting for enzyme costs in flux balance analysis reveals alternative pathways and metabolite stores in an illuminated arabidopsis leaf. Plant Physiol 169: 1671-1682

Colas Des Francs-Small C, Small I (2014) Surrogate mutants for studying mitochondrially encoded functions. Biochimie 100: 234-242

Croce R, Canino G, Ros F, Bassi R (2002) Chromophore Organization in the Higher-Plant Photosystem II Antenna Protein CP26. Biochemistry 41: 7334-7343

Cruz JA, Sacksteder CA, Kanazawa A, Kramer DM (2001) Contribution of Electric Field $(\Delta \psi)$ to Steady-State Transthylakoid Proton Motive Force (pmf) in Vitro and in Vivo. Control of pmf Parsing into $\Delta \psi$ and $\Delta \mathrm{pH}$ by lonic Strength. Biochemistry 40: 1226-1237

Dahal K, Martyn GD, Alber NA, Vanlerberghe GC (2016) Coordinated regulation of photosynthetic and respiratory components is necessary to maintain chloroplast energy balance in varied growth conditions. J Exp Bot erw469

Dinant M, Baurain D, Coosemans N, Joris B, Matagne RF (2001) Characterization of two genes encoding the mitochondrial alternative oxidase in Chlamydomonas reinhardtii. Curr Genet 39: 101-108

Dutilleul C, Driscoll S, Cornic G, De Paepe R, Foyer CH, Noctor G (2003) Functional mitochondrial complex I is required by tobacco leaves for optimal photosynthetic performance in photorespiratory conditions and during transients. Plant Physiol 131: 264-75

Eberhard S, Finazzi G, Wollman F-A (2008) The dynamics of photosynthesis. Annu Rev Genet 42: 463-515

Edwards K, Johnstone C, Thompson C (1991) A simple and rapid method for the preparation of plant genomic DNA for PCR analysis. Nucleic Acids Res 19: 1349

Finazzi G, Büschlen S, de Vitry C, Rappaport F, Joliot P, Wollman FA (1997) Function-directed mutagenesis of the cytochrome b6f complex in Chlamydomonas reinhardtii: involvement of the cd loop of cytochrome b6 in quinol binding to the $Q(0)$ site. Biochemistry 36: 2867-74

Fromm S, Braun H-P, Peterhansel C (2016a) Mitochondrial gamma carbonic anhydrases are required for complex I assembly and plant reproductive development. New Phytol 211: 194-207

Fromm S, Senkler J, Eubel H, Peterhänsel C, Braun H-P (2016b) Life without complex I: proteome analyses of an Arabidopsis mutant lacking the mitochondrial NADH dehydrogenase complex. J Exp Bot 67: 3079-93 
bioRxiv preprint doi: https://doi.org/10.1101/2020.11.20.390153; this version posted November 20, 2020. The copyright holder for this preprint (which was not certified by peer review) is the author/funder, who has granted bioRxiv a license to display the preprint in perpetuity. It is made available under aCC-BY-NC-ND 4.0 International license.

Furt F, Lemoi K, Tüzel E, Vidali L (2012) Quantitative analysis of organelle distribution and dynamics in Physcomitrella patens protonemal cells. BMC Plant Biol 12: 70

Gerotto C, Alboresi A, Meneghesso A, Jokel M, Suorsa M, Aro E-MEM, Morosinotto T (2016) Flavodiiron proteins act as safety valve for electrons in Physcomitrella patens. Proc Natl Acad Sci U S A 113: 12322 12327

Ghirardi ML, Posewitz MC, Maness P-C, Dubini A, Yu J, Seibert M (2007) Hydrogenases and hydrogen photoproduction in oxygenic photosynthetic organisms. Annu Rev Plant Biol 58: 71-91

Godaux D, Bailleul B, Berne N, Cardol P (2015) Induction of Photosynthetic Carbon Fixation in Anoxia Relies on Hydrogenase Activity and Proton-Gradient Regulation-Like1-Mediated Cyclic Electron Flow in Chlamydomonas reinhardtii. Plant Physiol 168: 648-58

Grechanik V, Romanova A, Naydov I, Tsygankov A (2020) Photoautotrophic cultures of Chlamydomonas reinhardtii: sulfur deficiency, anoxia, and hydrogen production. Photosynth Res 143: 275-286

Grossman AR, Catalanotti C, Yang W, Dubini A, Magneschi L, Subramanian V, Posewitz MC, Seibert M (2011) Multiple facets of anoxic metabolism and hydrogen production in the unicellular green alga Chlamydomonas reinhardtii. New Phytol 190: 279-288

Harris EH (2001) As a odel rganism. Mol Biol 52: 363-406

Järvi S, Suorsa M, Paakkarinen V, Aro E-M (2011) Optimized native gel systems for separation of thylakoid protein complexes: novel super- and mega-complexes. Biochem J 439: 207-14

Joliot P, Béal D, Joliot A (2004) Cyclic electron flow under saturating excitation of dark-adapted Arabidopsis leaves. Biochim Biophys Acta 1656: 166-76

Joliot P, Joliot A (2008) Quantification of the electrochemical proton gradient and activation of ATP synthase in leaves. Biochim Biophys Acta - Bioenerg 1777: 676-683

Joliot PA, Finazzi G (2010) Proton equilibration in the chloroplast modulates multiphasic kinetics of nonphotochemical quenching of fluorescence in plants. Proc Natl Acad Sci U S A 107: 12728-33

Klughammer C, Schreiber U (1994) An improved method, using saturating light pulses, for the determination of photosystem I quantum yield via P700+-absorbance changes at $830 \mathrm{~nm}$. Planta 192: 261-268

Kohzuma K, Bosco CD, Meurer J, Kramer DM (2013) Light- and Metabolism-related Regulation of the Chloroplast ATP Synthase Has Distinct Mechanisms and Functions. J Biol Chem 288: 13156

Kügler M, Jänsch L, Kruft V, Schmitz UK, Braun HP (1997) Analysis of the chloroplast protein complexes by blue-native polyacrylamide gel electrophoresis (BN-PAGE). Photosynth Res 53: 35-44

Kühn K, Obata T, Feher K, Bock R, Fernie AR, Meyer EH (2015) Complete Mitochondrial Complex I Deficiency Induces an Up-Regulation of Respiratory Fluxes That Is Abolished by Traces of Functional Complex I. Plant Physiol 168: 1537-49

Larosa V, Meneghesso A, La Rocca N, Steinbeck J, Hippler M, Szabò I, Morosinotto T (2018) Mitochondria Affect Photosynthetic Electron Transport and Photosensitivity in a Green Alga. Plant Physiol 176: 23052314

Lecler R, Vigeolas H, Emonds-Alt B, Cardol P, Remacle C (2012) Characterization of an internal type-II NADH dehydrogenase from Chlamydomonas reinhardtii mitochondria. Curr Genet 58: 205-16

Leon G, Holuigue L, Jordana X (2007) Mitochondrial Complex II Is Essential for Gametophyte Development in Arabidopsis. Plant Physiol 143: 1534-1546

Li Z, Wakao S, Fischer BB, Niyogi KK (2009) Sensing and responding to excess light. Annu Rev Plant Biol 60: 239-60

Ligas J, Pineau E, Bock R, Huynen MA, Meyer EH (2019) The assembly pathway of complex I in Arabidopsis thaliana. Plant J 97: 447-459

Massoz S, Larosa V, Plancke C, Lapaille M, Bailleul B, Pirotte D, Radoux M, Leprince P, Coosemans N, Matagne RF, et al (2013) Inactivation of genes coding for mitochondrial Nd7 and Nd9 complex I subunits in Chlamydomonas reinhardtii. Impact of complex I loss on respiration and energetic metabolism. Mitochondrion. doi: 10.1016/j.mito.2013.11.004

Møller IM (2001) P LANT M ITOCHONDRIA AND O XIDATIVE S TRESS : Electron Transport, NADPH Turnover, and Metabolism of Reactive Oxygen Species. Annu Rev Plant Physiol Plant Mol Biol 52: 561-591

Neff MM, Fankhauser C, Chory J (2000) Light: an indicator of time and place. Genes Dev 14: 257-271 Nishio JN, Whitmarsh J (1993) Dissipation of the Proton Electrochemical Potential in Intact Chloroplasts (II. 
bioRxiv preprint doi: https://doi.org/10.1101/2020.11.20.390153; this version posted November 20, 2020. The copyright holder for this preprint (which was not certified by peer review) is the author/funder, who has granted bioRxiv a license to display the preprint in perpetuity. It is made available under aCC-BY-NC-ND 4.0 International license.

The pH Gradient Monitored by Cytochrome f Reduction Kinetics). Plant Physiol 101: 89-96

Noguchi K, Yoshida K (2008) Interaction between photosynthesis and respiration in illuminated leaves. Mitochondrion 8: 87-99

Peters K, Nießen M, Peterhänsel C, Späth B, Hölzle A, Binder S, Marchfelder A, Braun H-P (2012) Complex Icomplex II ratio strongly differs in various organs of Arabidopsis thaliana. Plant Mol Biol 79: 273-284

Pineau B, Layoune O, Danon A, De Paepe R (2008) L-galactono-1, 4-lactone dehydrogenase is required for the accumulation of plant respiratory complex I. J Biol Chem 283: 32500-32505

Porra RJ, Thompson WA, Kriedemann PE (1989) Determination of accurate extinction coefficients and simultaneous equations for assaying chlorophylls $a$ and $b$ extracted with four different solvents: verification of the concentration of chlorophyll standards by atomic absorption spectroscopy. Biochim Biophys Acta - Bioenerg 975: 384-394

Radin I, Mansilla N, Rödel G, Steinebrunner I (2015) The Arabidopsis COX11 Homolog is Essential for Cytochrome c Oxidase Activity. Front Plant Sci 6: 1-17

Rak M, Rustin P (2014) Supernumerary subunits NDUFA3, NDUFA5 and NDUFA12 are required for the formation of the extramembrane arm of human mitochondrial complex I. FEBS Lett 588: 1832-1838

Sacksteder CA, Kramer DM (2000) Dark-interval relaxation kinetics (DIRK) of absorbance changes as a quantitative probe of steady-state electron transfer. Photosynth Res 66: 145-58

Sakakibara K, Nishiyama T, Sumikawa N, Kofuji R, Murata T, Hasebe M (2003) Involvement of auxin and a homeodomain-leucine zipper I gene in rhizoid development of the moss Physcomitrella patens. Development 130: 4835-46

Salinas T, Larosa V, Cardol P, Maréchal-Drouard L, Remacle C (2014) Respiratory-deficient mutants of the unicellular green alga Chlamydomonas: a review. Biochimie 100: 207-18

Schimmeyer J, Bock R, Meyer EH (2016) L-Galactono-1,4-lactone dehydrogenase is an assembly factor of the membrane arm of mitochondrial complex I in Arabidopsis. Plant Mol Biol 90: 117-126

Schönfeld C, Wobbe L, Borgstädt R, Kienast A, Nixon PJ, Kruse O (2004) The nucleus-encoded protein MOC1 is essential for mitochondrial light acclimation in Chlamydomonas reinhardtii. J Biol Chem 279: $50366-$ 74

Senkler J, Rugen N, Eubel H, Hegermann J, Braun H-P (2018) Absence of Complex I Implicates Rearrangement of the Respiratory Chain in European Mistletoe. Curr Biol 28: 1606-1613.e4

Shameer S, Ratcliffe RG, Sweetlove $\amalg$ (2019) Leaf Energy Balance Requires Mitochondrial Respiration and Export of Chloroplast NADPH in the Light. Plant Physiol 180: 1947-1961

Stiehl HH, Witt HT (1969) Quantitative Treatment of the Function of Plastoquinone in Photosynthesis. Zeitschrift für Naturforsch B 24: 1588-1598

Storti M, Alboresi A, Gerotto C, Aro E-M, Finazzi G, Morosinotto T (2019) Role of cyclic and pseudo-cyclic electron transport in response to dynamic light changes in Physcomitrella patens. Plant Cell Environ 42: 1590-1602

Storti M, Segalla A, Mellon M, Alboresi A, Morosinotto T (2020) Regulation of electron transport is essential for photosystem I stability and plant growth. New Phytol nph.16643

Subrahmanian N, Remacle C, Hamel PP (2016) Plant mitochondrial Complex I composition and assembly: A review. Biochim Biophys Acta - Bioenerg 1857: 1001-1014

Takizawa K, Cruz JA, Kanazawa A, Kramer DM (2007) The thylakoid proton motive force in vivo. Quantitative, non-invasive probes, energetics, and regulatory consequences of light-induced pmf. Biochim Biophys Acta 1767: 1233-1244

Takizawa K, Kanazawa A, Kramer DM (2008) Depletion of stromal Pi induces high "energy-dependent" antenna exciton quenching (qE) by decreasing proton conductivity at CF O-CF1 ATP synthase. Plant, Cell Environ 31: 235-243

Vanlerberghe GC, Dahal K, Alber NA, Chadee A (2020) Photosynthesis, respiration and growth: A carbon and energy balancing act for alternative oxidase. Mitochondrion 52: 197-211

Vidal G, Ribas-Carbo M, Garmier M, Dubertret G, Rasmusson AG, Mathieu C, Foyer CH, De Paepe R (2007) Lack of respiratory chain complex I impairs alternative oxidase engagement and modulates redox signaling during elicitor-induced cell death in tobacco. Plant Cell 19: 640-655

Wang C, Shikanai T (2019) Modification of Activity of the Thylakoid $\mathrm{H}(+) / \mathrm{K}(+)$ Antiporter KEA3 Disturbs $\Delta \mathrm{pH}-$ 
bioRxiv preprint doi: https://doi org/10.1101/2020.1120.390153; this version posted November 20,2020. The copyright holder for this preprint (which was not certified by peer review) is the author/funder, who has granted bioRxiv a license to display the preprint in perpetuity. It is made available under aCC-BY-NC-ND 4.0 International license.

Dependent Regulation of Photosynthesis. Plant Physiol 181: 762-773

Watt IN, Montgomery MG, Runswick MJ, Leslie AGW, Walker JE (2010) Bioenergetic cost of making an adenosine triphosphate molecule in animal mitochondria. Proc Natl Acad Sci U S A 107: 16823-7

Witt HT (1979) Energy conversion in the functional membrane of photosynthesis. Analysis by light pulse and electric pulse methods. The central role of the electric field. BBA Rev Bioenerg 505: 355-427

Yang W, Catalanotti C, Wittkopp TM, Posewitz MC, Grossman AR (2015) Algae after dark: mechanisms to cope with anoxic/hypoxic conditions. Plant J 82: 481-503

Yoshida K, Noguchi K (2011) Interaction Between Chloroplasts and Mitochondria: Activity, Function, and Regulation of the Mitochondrial Respiratory System during Photosynthesis. In F Kempken, ed, Plant Mitochondria. Springer New York, New York, NY, pp 383-409

Zalutskaya Z, Lapina T, Ermilova E (2015) The Chlamydomonas reinhardtii alternative oxidase 1 is regulated by heat stress. Plant Physiol Biochem 97: 229-234

Zhang L-T, Zhang Z-S, Gao H-Y, Meng X-L, Yang C, Liu J-G, Meng Q-W (2012) The mitochondrial alternative oxidase pathway protects the photosynthetic apparatus against photodamage in Rumex K-1 leaves. BMC Plant Biol 12: 40 